\title{
LA PARODIA RADICAL DE RODRIGO LIRA
}

\author{
Natalia Canales ${ }^{1}$
}

\section{Resumen/Abstract}

Proyecto de Obras Completas, es uno de los experimentos más radicales de la poesía nacional. En su composición estructural, Rodrigo Lira mezcla elementos visuales y estéticos, además de incluir constantes referencias a otros autores (como Lihn, Parra y Huidobro) a modo de intertextualidad. De esta forma va extremando los recursos liricos y lingüísticos hasta lograr una visión frenética del mundo que lo rodea. La radicalización de la parodia es la forma en que encuentra salida a sus sentimientos más recónditos de desamparo e inconformismo. Aquí se encuentra el pilar sobre el cual postulo alejar su poesía del pastiche: la profundidad que encierran los versos de Lira. Baso mi análisis en Proyecto de obras completas texto publicado en 1983 cuya segunda edición fue lanzada en el año 2003.

Palabras clave: parodia radical, intertextualidad, posmodernismo

\section{THE RADICAL PARODY OF RODRIGO LIRA}

Proyecto de Obras Completas, is one of the most radical experiments of poetry. In its structural composition, Rodrigo Lira blend aesthetic and visual elements plus include constant references to other authors (as Lihn, Parra and Huidobro) as intertextuality. This is extreme lyrics and linguistic resources to achieve a frantic vision of the world around him. The radicalization of the parody is how they found out their innermost feelings of helplessness and conformity. Here is the pillar on which I postulate his poetry away from the pastiche: the depth behind the verses of Lira. I Bas my analysis in Proyecto de Obras Completas, text published in 1983 whose second edition was launched in 2003.

Keywords: radical parody l intertextuality, postmodernism

\footnotetext{
${ }^{1}$ Chilena, Universidad Católica de Chile. E-mail: nvcanale@uc.cl

Recibido: 02 septiembre 2018

Aceptado: 15 abril 2019
} 


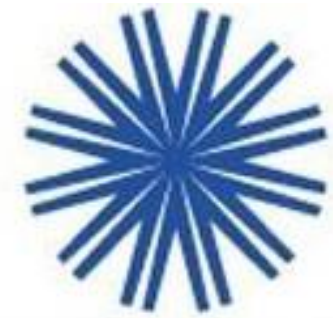

Proyecto de Obras Completas es la edición póstuma de un conjunto de poemas que Rodrigo Lira seleccionó antes de suicidarse. Es también un ejercicio de posmodernismo, donde los recursos literarios, artísticos y lingüísticos se han extremado para dar forma a una nueva concepción de la poesía. Es una obra donde se desdibuja un amplio conocimiento del mundo "pop y pap art”, y un extenso trabajo tipográfico, colmado de negritas, cursivas, mayúsculas y diversos tipos de diagramación. Sin lugar a dudas, el trabajo que Lira hacía al alterar las concepciones tradicionales de la escritura respondía a su deseo de conectar la palabra escrita con el vértigo del verbo hablado. Aquí se enraíza también la manifestación más profunda de su inconformismo frente a la poesía tradicional. Su parodia se sustenta en la base de la intertextualidad, y la radicaliza al extremo, no solo superponiendo textos, sino que, destruyéndolos, desviándolos, deconstruyéndolos y creando a partir de sus restos. Esta definición de la poesía de Lira lo aleja completamente de la idea de pastiche, pues la llena de sentido y profundidad.

Me abocaré, por lo tanto, a descifrar cómo el sentido de sus poemas se arquea hasta la disonancia, y se oculta en las desviaciones, ya no solo gramaticales, sino también diagramacionales de sus versos. Temporizaré su obra como posmoderna, mas haré notar como sin importar la época en que fue escrita, la poesía de Rodrigo Lira es independiente de clasificaciones generacionales. Si Diego Maquieira lo sepultó por perdedor, aquí se le intentará resucitar a la gloria terrenal de los iluminados. ${ }^{2}$

\section{Lira, el posmodernista}

Para ubicar a Lira como poeta posmodernista, debemos en primer lugar delimitar el espacio por donde su poesía se mueve. Fredric Jameson (1991) sitúa el movimiento posmodernista a fines de los cincuenta o principios de los sesenta como consecuencia de la ruptura o coupure del movimiento modernista. La crisis de las vanguardias desembocó en una serie de movimientos menores, anclados en el escepticismo, la desconfianza de la razón y una crítica poderosa a las concepciones estilísticas predominantes. Desde este lugar Lira comienza a escribir sus poemas, marcadamente burlescos y ácidos como una forma de reírse, de sí mismo, de todo y de todos. Así también, el proceso posmoderno es, según Jameson, de carácter

\footnotetext{
${ }^{2}$ Diego Maquieira declara, en una entrevista publicada en disorder.cl: "En el caso de Lira, si parte con el caos y acaba con el caos, eso explica su fracaso. Lira fracasó en ese sentido".
} 
eminentemente esquizofrénico y para esto se apoya en la definición de Lacan de la esquizofrenia como "una ruptura de la cadena del significante" (1991: 63). Visto así, Lira hace que su poesía desestabilice la relación dialógica que hay entre el poema y su significación. Otro de los rasgos que determinan la poesía de Lira como posmodernista es su marcado gusto por la estética; en sus trabajos se advierte una especial dedicación a la diagramación, la composición, la utilización de técnicas lingüísticas y todo aquello que le estuviera al alcance para prodigar belleza a su obra. Uno de los recursos que más utilizaba era el de la intertextualidad, mediante el cual se burlaba de lo que en ese entonces era el mundo literario chileno. Jameson establece que este tipo de copia es "la imitación de una mueca determinada, un discurso que habla una lengua muerta: pero se trata de la repetición neutral de esa mímica [...] desligada del impulso satírico, desprovista de hilaridad" (1991: 43), y lo titula como pastiche. Sin embargo, la parodia de Lira está lejos de ser vacía, pues su burla es una crítica al lirismo sacro, encarnado en poetas con deseos de divinidad. Es este el punto donde el poeta se aleja de la teoría de Jameson, si bien su poesía se establece en el humor, la burla y la parodia, su espectro está ligado a una actitud contestataria y no a una producción en serie, sistematizada en el mercado. Estos son los tres puntos donde la poesía de Lira confluye: la crítica a sus predecesores y contemporáneos, la estridencia de los recursos y la radicalización de la parodia. Ellos marcan la necesidad del autor de hacer proliferar en la palabra escrita el sonido de la voz.

Por otro lado, el posmodernismo como movimiento artístico esta franqueado por una paradoja esencial: su definición contiene aquello que quiere cuestionar. De esta misma forma los poemas de Lira cogen los recursos del lirismo que intentaba burlar. Esto ocurre principalmente a través de las referencias recurrentes a otros autores; a modo de ejemplo, el epígrafe de "doq.mentos del antayer Qatro gatos" es un poema de Gonzalo Rojas, en "Ars Poetique" parafrasea a Huidobro, deformando el "Arte Poética" de éste, pero dejando su huella para que el texto fuera levemente reconocible. Existe en ambos un deseo de mantener viva la figura del autor primario (especialmente en "doq.mentos..." donde la reproducción del poema original se hace sin ninguna intervención) como una forma de negación, pero solo de forma parcial, pues sigue alimentándose de ellos. Así, se desdibuja su propio contrasentido:

pendiente -O "cuesta" arriba Paréntesis: (la palabra "cuesta" está arriba de la palabra "arriba": esta antes: se lee de arriba hacia abajo, 
y, arribando arriba [...] (Lira, 2003: 90)

\section{Espectador imparcial}

Este contrasentido se evidencia también en su percepción del lenguaje, frente al cual toma una postura escéptica. Desconfía de la palabra escrita, que no termina de representar todo aquello que él quiere expresar. Aun así, experimenta con ella buscando la forma en que pudiera transformarla en sonido. En esto, Lira demuestra su determinación rupturista, deforma hasta el límite de lo permitido, yendo en ocasiones mucho más allá, creando un nuevo orden:

Fe o los enK.jes de

las enaguas y las $\mathrm{C}^{\circ}$ tizaciones $\mathrm{C}^{\circ}$ rrespondientes. Los

Q.atro

gatos

son K.apos y K:paces: ni el Q.qlux clan ni el Q.co son K.paC.s de K.strar a los

Q.atro Q.atro

gatos gatos (97)

Lira introduce el habla coloquial en su discurso poético, como una forma de recuperación de su propio lenguaje, intenta desarrollar una lengua sobre su lengua, realizando juegos tipográficos, mezclando abreviaturas, desarmando y rearmando palabras, para finalmente ponerlas en el papel, pues le interesaba más la forma fonética que su valor referencial. Las imágenes también son parte importante en sus textos. Pero contrario a lo que se puede pensar, Lira las crea a partir de elementos caligráficos, semejante a los caligramas de Huidobro, pero al contrario de éste, su fin es el de la burla hacia la lengua. Como un ilusionista, pretendía embelesar a quienes leyeran sus escrituraciones (pues él se negaba a llamarlas poemas) para hacerles creer que leían un dibujo.

Ante la insuficiencia del significado denotativo de las palabras, las desfiguraba hasta hacerlas explosar y mostrar en su esplendor el significado que las normas de la gramaticalidad les obligaban a ocultar. Su máximo brillo era para Lira la ausencia de orden retórico, la inexistencia del valor ortográfico. Llevaba al máximo el lenguaje poético, lo transforma en multívoco, como connotativo, al punto de dejarlo vacío de todo significado 
Por esta no creencia en la palabra fue que introdujo en sus creaciones referencia a otras lenguas. El inglés, el latín, el francés y la imitación (caricaturesca) de un oriental hablando español aparecen una vez más como intento de explotar al máximo las capacidades comunicativas que el habla le proporcionaba. En "verano de 1979: comienzo de un nuevo block", Lira haría patente su inconformismo lingüístico:

EN EL LIMITE del lenguaje

me canso

Entonces, cualquier palabra es un regreso, un mas-acá

o tal vez

nada más que la cabriola, la pirueta, el cohete $\mathrm{o}$

el petardo: ruido

breve, todo

pasa

¿Hay límites en el lenguaje?

$\mathrm{O}$ solo falta que decir: el

sentido. ¿Y el sonido? ¿La ráfaga

de palabras, el e st a 11 id o?

Ruido breve,

todo pasa. (153)

\section{El verso como ganzúa}

El humor negro es otro de los rasgos propios en sus versos, Lira se burlaba tanto de otros como de sí mismo, como una declaración de principios. Analizaba el mundo no desnudo propiamente, pero por lo menos en camisa. Esto le permitió decir en broma lo que sentía en serio, desvestía sus propias falencias y miserias a través del chiste. Su condición de poeta mal valorado quedaba de manifiesto en sus críticas maliciosas al mundo lírico. Ridiculizaba a sus pares y sus motivos literarios, consideraba que los poetas tradicionales desperdiciaban su tiempo intentando hermosear a través de palabras rebuscadas y sinsentido. Para él la poesía era fuente de cotidianeidad, por lo mismo, el poeta creador, semidiós y divinizado, eran solo un invento de la sin razón predominante. Por otro lado, la visión parriana de la poesía (el poeta bajado del Olimpo) le parece exigua, el no ve el autor como un hombre corriente, más bien siente que el trabajo poetico es una forma de mendigar: "El Autor pide al Lector diScurpas por la molestia (Su Propinaes Misuerdo)" (33). Me atrevo a conjeturar que esta mirada estaba influenciada por la poca aceptación que 
generaba su trabajo dentro de su círculo familiar quienes no miraban con beneplácito sus tambaleantes creaciones.

Lira dialoga con los textos de quienes ridiculiza, transforma las palabras para enrostrar a los poetas su falta de asertividad. Su burla es extrema, parodia los textos hasta la neurosis. Quiere robar desde dentro de los versos, para otorgarles una nueva forma, al igual que un Robin Hood de la poesía, el hurto de Lira intenta devolver la lírica al estado natural desde donde él asume que esta provino.

Cree también que la belleza está en lo grotesco y la sublimidad cantada por los vates se ha transformado en algo sin sentido, vacío y absurdo. Su convicción es que la poesía está muerta y cuelga como recuerdo fosilizado sin valor, o bien, se utiliza de forma comercial y vendible y se fabrica en serie tal como los autos de Ford:

Versos tristes y acabados, con olor prostibular: verbo vencido, agotado temprano, tempranero malevaje/ -poesía decadente con olor a vieja bruja, o -poemas descocados con plumas para can can: jolgorio de miusic jol, gorgoritos de soprano/ -poesía desflecada de aroma crepuscular, de eyacular prematura: intento impotente de poetiso inmaduro: todo en vano -poesía recatada de encajes en las enaguas -poesía para guaguas -para la mujer soñada -poesía balbuceada, mal trazada en el papel blanco, el papel, casi siempre, o celeste color valium para el poeta maldito que quizá sacó ya algún librito, e inmortaliza sus gritos al leer ante una audencia y así shockear la conciencia del que escucha ¿atentamente? -poemas para la gente con la mente bien lustrada -poemillos infantiles de poetisas rosadas -la prosodia bien pausada del poeta ya fogueado en escenarios prestados con muy buena voluntad (124) 
El epígrafe de "Ars Poetique" dedica el poema a "la galería imaginaria" (33), preconcibiendo que los lectores implícitos se habían explicitado para fugarse, lo que termina frustrándolo. La parodia surge en sus textos como respuesta a esta frustración. Pero no se conforma solo con reírse, no, quiere también (de) construir de forma subversiva, reacomodando por sobre los modelos, sus propios sentidos poéticos, lo que le otorga a los versos una dirección heterogénea.

Herrero-Olaizola dice que "uno de los puntos de contacto entre el posmodernismo literario y la parodia es el carácter (de) formativo: esto es, de dar forma a una escritura a base de deformar un modelo anterior" (Herrero-Olaizola, 2000: 41). Lira, toma a Huidobro, lo roba y destruye. Al igual como la mimesis literaria mata la realidad, él sepulta los versos, los crema y los convierte en vasijas de greda. Su parodia no es simplemente un recurso estructural, es una crítica a él mismo por ser un simple peón, a los poetas por auto institucionalizarse y al lenguaje por insuficiente.

A pesar de ser un espectador imparcial (que parodia sin tomar partido), Lira no deja de analizar las circunstancias que lo rodean. La censura, el gobierno militar y la paulatina instauración del neoliberalismo, se ven retratadas en parte de sus versos, veladas bajo el rótulo de graciosidad:

\section{Paredes de Oído!}

cae un Rocket pasa un Mirage

los ventanales quedaron temblando (33)

\section{El verso como Pacman ${ }^{3}$}

Sin duda al hablar de Lira no puedo obviar un recurso que atraviesa gran parte de su obra: el de la intertextualidad, intrínsecamente relacionado con el fenómeno paródico. Bajtin vislumbra el término al afirmar que en todos los textos existen además de la voz del autor otras voces que en forma dialógica establecen relaciones:

\section{Ars Poetique para la galería imaginaria}

\footnotetext{
${ }^{3}$ Pac-Man o Comecocos es un videojuego arcade creado por el diseñador de videojuegos Toru Iwatani de la empresa Namco, y distribuido por Midway Games al mercado estadounidense a principios de los años 1980. Su objetivo era comer la mayor cantidad de cocos mientras se era perseguido por cuatro monstruos.
} 
Que el verso sea como una ganzúa

Para entrar a robar de noche

Al diccionario a la luz

De una linterna

sorda como

Tapia

Muro de los Lamentos

Lamidos [...]

Estamos en el siglo de las neuras y las siglas

y las siglas

son los nervios, son los nervios

El vigor verdadero reside en el bolsillo

es la chequera

El músculo se vende en paquetes por Correos

la ambición

no descansa la poesía

está c

ol

g

an

do

en la dirección de Bibliotecas Archivos y Museos en Artí

culos de lujo, de primera necesidad,

oh, poetas! No cantéis

a las rosas, oh, dejadlas madurar y hacedlas

mermelada de mosqueta en el poema [...] (33)

En estos versos se puede apreciar que el autor no ejerce una mera cita a un poema huidobriano, sino más bien, que ha intentado devorárselos, pero no pudiendo digerirlos, los ha devuelto como un nuevo signo, que altera al original hasta hacerlo casi irreconocible. La apropiación de los versos por parte de Lira busca desestabilizar el concepto canónico de lo literario, de forma hipertextual, es decir, de una forma que no es el comentario. Anclado en su desapego por la lírica tradicional (que como ya mencioné genera en el autor una situación paradójica), utiliza este recurso para deslegitimizar a este poeta creador, retornándolo a la calidad de pordiosero, que limosneando en el verso pretende auto imponerse una condición de ser supremo. Pero Lira no se limita a transformar el verso en objeto de mendicación, va más allá y lo muta a un elemento para robar en la palabra. La primera y la última parte del poema son una clara alusión al "Arte Poética" de Huidobro, que es, quizá, el más claro ejemplo de lo que este convenía era su labor como vate. Hay un intento de absorción de las ideas de éste sobre lo que es poesía, pero Lira, que no compartía este concepto, termina escupiendo el original como una forma despreciativa. La intertextualidad, entonces pasa 
a ser un medio mediante el cual intenta comerse la poesía, mientras se siente perseguido por sus fantasmas personales.

\section{El último manifiesto}

El aspecto privado de la vida de Rodrigo Lira es un punto que trasciende a su obra literaria. La incomprensión y falta de apoyo de sus padres a su labor lírica y sus malas experiencias erótico sentimentales lo llevaron a reformular su trabajo poético y encauzarlo por una senda más desgarradora que, sin alejarse de su humor ácido, daba cuenta de su profunda crisis existencial. Esto sumado a una esquizofrenia y su exacerbado escepticismo derivaría en su suicidio la mañana del 26 de diciembre de 1981 (misma hora y fecha de su nacimiento) "Q.atro gatos s" pareciera no ser únicamente un manifiesto, sino también una despedida. No solo lanza sus propias directrices, también anticipa su adiós inminente de este mundo. Aludiendo a un poema de Gonzalo Rojas pareciera vislumbrar el paso siguiente en su parodia radicalizadora:

Coronado de laureles ser, y después estar en el recuerdo, así quedar al pasar a mejor vida (93)

Así, hace obvia su decisión de eliminarse, quizá, último gesto de su rebeldía. Su parodia, su queja intensa quedarían acallados luego de su muerte. La recopilación de su obra, más que darnos una visión descriptiva, quiere que nos riamos, del mundo, de la vida, de Dios y de los hombres. Y fue sin quererlo esto lo que transformó la obra de Lira en una de las más influyentes de las nuevas letras nacionales.

\section{Conclusión}

La poesía de Rodrigo Lira es una de las más rupturistas de los años 80. No solo plantea una visión crítica de lo que le arte debiera ser, sino que además deconstruye su forma y manifestaciones, situándonos ante una nueva forma de interpretación de la realidad. Una poesía juguetona, alejada de la situación parsimoniosa en la que ésta se encontraba, luego de las décadas previas. Lira no solo plantea un cambio en el fondo, al extremar el recurso de la parodia, también radicaliza su forma estética, transformando sus versos en rompecabezas literarios. 
Lira desafió la censura de su época, utilizando recursos propios de la poesía, pero llevando su obra más allá al saltarse las convenciones tradicionales sobre la lírica. Eso le da un carácter radical a su parodia, lo transforma en un poeta del posmodernismo, con su discurso fragmentado y ecléctico, dotando su obra de una nueva perspectiva referente a la creación literaria y dando un salto cualitativo respecto de sus pares de la época. Esto último, es reconocido incluso por otros poetas contemporáneos a él como Lihn, y otros un poco más distantes en el tiempo como Roberto Bolaño, quién lo nombra como uno de los seis tigres de la poesía chilena. Su voz es una de las más importantes de la literatura nacional, debido a las características propias de sus letras, las que han inspirado a poetas de las nuevas generaciones, por lo que destacar el carácter novedoso, lúdico y paródico de sus textos, es una reivindicación póstuma a su figura.

\section{Referencias bibliográficas}

Baudrillard, J. (1985). La posmodernidad. Barcelona: Kairós. (2001). La transparencia del mal: ensayos sobre los fenómenos extremos. Barcelona : Anagrama.

Blume, J. (23 de Junio de 2007). Rodrigo Lira el poeta posmoderno. Obtenido de Letras.s5: www.letras.s5.com/archivolira.html

Eagleton, T. (1997). Las ilusiones del posmodernismo. Buenos Aires: Paidós.

Herrero-Olaizola, A. (2000). Narrativas Híbridas: parodia y posmodernismo en la ficción contemporánea de las Américas. Madrid: Verbum.

Jameson, F. (1991). El posmodernismo, o la lógica cultural del capitalismo avanzado. Barcelona: Paidós. Lira, R. (2003). Proyecto de obras completas. Santiago: Editorial Universitaria.

Maquieria, D. (23 de junio de 2007). No quiero que me lean, quiero que me aprendan de memoria. (R. Arriagada, Entrevistador)

Subirats, E. (1985). La crisis de las vanguardias y la cultura moderna. Madrid: Ediciones libertarias. 